Provided for non-commercial research and education use. Not for reproduction, distribution or commercial use.

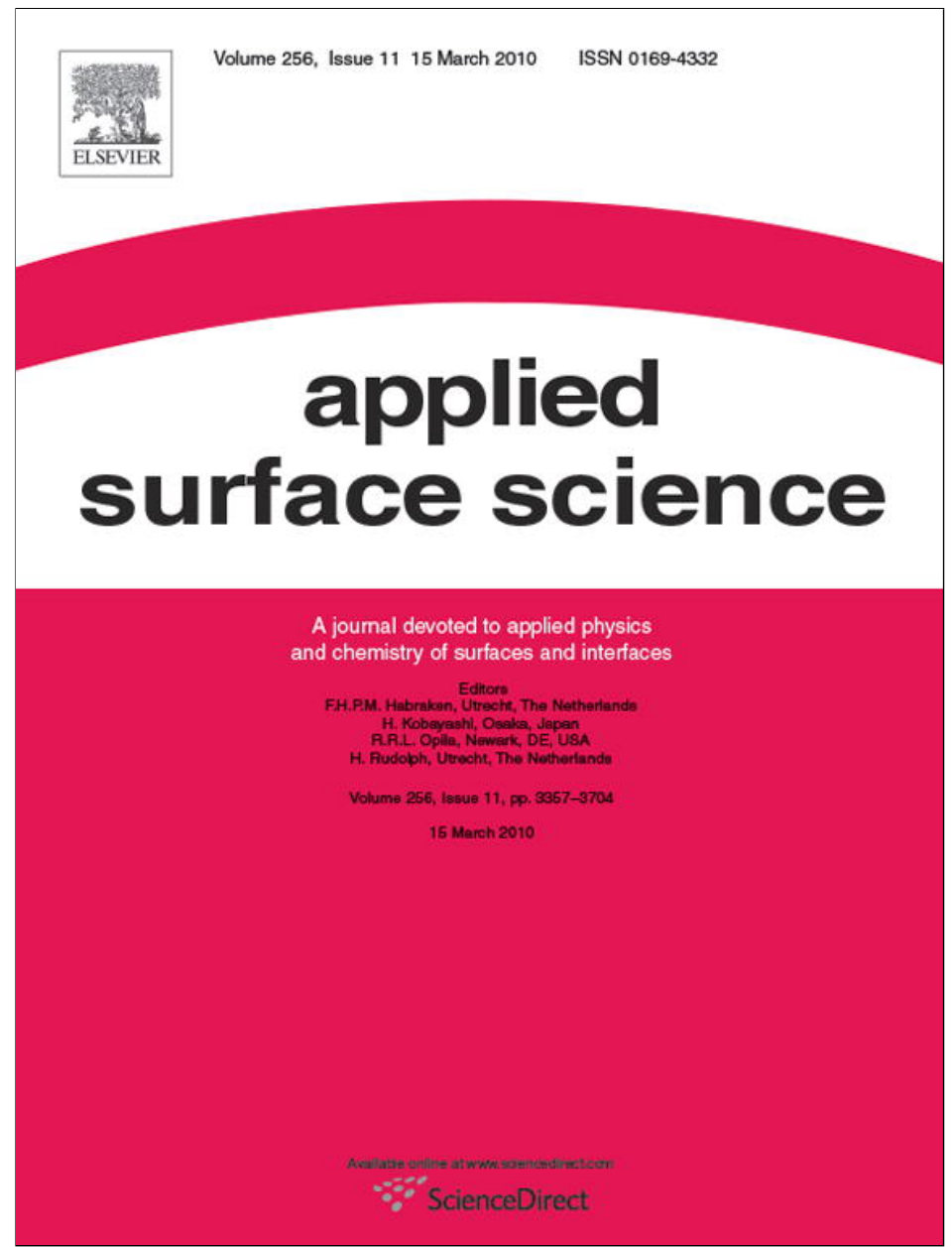

This article appeared in a journal published by Elsevier. The attached copy is furnished to the author for internal non-commercial research and education use, including for instruction at the authors institution and sharing with colleagues.

Other uses, including reproduction and distribution, or selling or licensing copies, or posting to personal, institutional or third party websites are prohibited.

In most cases authors are permitted to post their version of the article (e.g. in Word or Tex form) to their personal website or institutional repository. Authors requiring further information regarding Elsevier's archiving and manuscript policies are encouraged to visit:

http://www.elsevier.com/copyright 


\title{
The control of the diameter of the nanorods prepared by dc reactive magnetron sputtering and the applications for DSSC
}

\author{
Lijian Meng a,b,c,*, Tong Ren ${ }^{\mathrm{a}}$, Can Li ${ }^{\mathrm{a}, * *}$ \\ a State Key Laboratory of Catalysis, Dalian Institute of Chemical Physics, Chinese Academy of Sciences, 457 Zhongshan Road, Dalian 116023, China \\ ${ }^{\mathrm{b}}$ Departamento de Física, Instituto Superior de Engenharia do Porto, Rua Dr. António Bernardino de Almeida, 431, 4200-072 Porto, Portugal

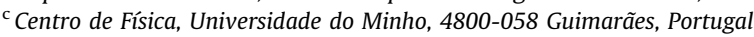

\section{A R T I C L E I N F O}

\section{Article history:}

Received 24 September 2009

Received in revised form 31 December 2009

Accepted 31 December 2009

Available online 18 January 2010

\section{Keywords:}

$\mathrm{TiO}_{2}$

Nanorod

Sputtering

DSSC

\begin{abstract}
A B S T R A C T
The $\mathrm{TiO}_{2}$ nanorod arrays, with about $1.8 \mu \mathrm{m}$ lengths, have been deposited on ITO substrates by dc reactive magnetron sputtering at different target-substrate distances. The average diameter of these nanorods can be modified from about 45 to $85 \mathrm{~nm}$ by adjusting the target-substrate distance from 90 to $50 \mathrm{~mm}$. These nanorods are highly ordered and perpendicular to the substrate. Both XRD and Raman measurements show that the nanorods prepared at different target-substrate distances have only an anatase $\mathrm{TiO}_{2}$ phase. The nanorods prepared at the target-substrate distance less than $80 \mathrm{~mm}$ have a preferred orientation along the (2 20 ) direction. However, this preferred orientation disappears as the target-substrate distance is more than $80 \mathrm{~mm}$. These $\mathrm{TiO}_{2}$ nanorods have been used as the electrodes for dye-sensitized solar cells (DSSCs). The highest conversion efficiency, about $4.78 \%$, has been achieved for $\mathrm{TiO}_{2}$ nanorods prepared at $80 \mathrm{~mm}$ target-substrate distance.
\end{abstract}

() 2010 Elsevier B.V. All rights reserved.

\section{Introduction}

The research and development efforts have been intensified for finding new sources of renewable energy such as photovoltaic, tidal power, or wind energy in recent years as the amount of fossil fuels available to burn decreasing at an alarming rate. Considering the abundance of solar radiation reaching the earth, solar energy is a strategic energy source if cost-effective solar cell technologies are widely developed and implemented. Since O'Regan and Gratzel first reported the highly efficient DSSC using the nanoporous and interconnected $\mathrm{TiO}_{2}$ particles as an electrode [1], a porous thin film composed of $\mathrm{TiO}_{2}$ nanosize particles has been widely used as an electrode in DSSC to achieve a high surface area for adsorption of a large number of dye molecules, and then a significant increasing of the photocurrent [2-13]. Research work done within the last decade has proved that DSSC using titanium dioxide as the electrode is cost-effective, highly productive and easy to produce. Colloidal chemistry is almost a standard way to prepare nanoporous $\mathrm{TiO}_{2}$ films for DSSC applications. Although the solgel technique is widely used, it produces films comprising of nanoparticles that are randomly oriented which reduces the

* Corresponding author at: Departamento de Física, Instituto Superior de Engenharia do Porto, Rua Dr. António Bernardino de Almeida, 431, 4200-072 Porto, Portugal. Tel.: +351 962325429; fax: +351 228321159 .

** Corresponding author.

E-mail addresses: ljm@isep.ipp.pt (L. Meng), canli@dicp.ac.cn (C. Li). surface area of the film exposed to the dye. Further, the small crystal size, typically less than $20 \mathrm{~nm}$, causes two problems: firstly small size means that there is no space charge area and consequently no electrode/electrolyte interface energy barrier, which may contribute to photoelectron recombination. Secondly, the small crystal size causes low electron diffusion coefficient. To overcome these problems, $1 \mathrm{D}$ nano-structured $\mathrm{TiO}_{2}$ material, such as nanorod [14-19], nanotube [20-22] and nanowire [23-25] has been used as an electrode for DSSC applications because the interconnection between crystalline $\mathrm{TiO}_{2}$ particles are greatly decreased by using the 1D nano-structured materials in comparison with a porous $\mathrm{TiO}_{2}$ thin film composed of accumulated nanosized particles. Recently the conversion efficiency of the DSSC assembled with these nano-structured $\mathrm{TiO}_{2}$ materials has been improved greatly $[17,20,25]$. All these $1 \mathrm{D}$ nano-structured $\mathrm{TiO}_{2}$ materials are made by chemical methods. The reactive sputtering technique has emerged as one of the most promising techniques. This technique permits large-scale deposition of high quality films. Additionally, the process parameters are easily controlled and a metal target can be used. The other advantage of this technique is that it does not require a heat treatment until $450^{\circ} \mathrm{C}$, contrary to sol-gel technique. Therefore, a polymer substrate can be used. In addition, the sputtered $\mathrm{TiO}_{2}$ films have a better electronic transport than $\mathrm{TiO}_{2}$ prepared by sol-gel technique [26]. Gomez et al. have studied DSSC assembled with $\mathrm{TiO}_{2}$ films prepared by dc reactive magnetron sputtering technique at the beginning of this century [26-30]. The highest conversion efficiency they have got is $4 \%$ for as-deposited $\mathrm{TiO}_{2}$ electrode [28]. Recent 2 years, there are other 
works reported for $\mathrm{TiO}_{2}$ films prepared by sputtering technique for DSSC applications [31-36]. However, the conversion efficiencies reported in these works are less than $4 \%$ which has been achieved by Gomez before.

In this study, $\mathrm{TiO}_{2}$ nanorods with different diameters have been prepared by dc reactive magnetron sputtering technique by adjusting the target-substrate distance. The properties of these nanorods and effect of the diameter on DSSC conversion efficiency have been reported.

\section{Experimental procedures}

The $\mathrm{TiO}_{2}$ nanorod arrays were prepared on the commercial ITO (sheet resistance of $20 \Omega$ per square) substrates by dc reactive magnetron sputtering technique using a commercial sputtering system equipped with a turbo molecular pumping system. A titanium metal disk (60 $\mathrm{mm}$ in diameter and $3 \mathrm{~mm}$ in thickness) with a purity of $99.99 \%$ was used as the target. After pumping down to $1 \times 10^{-3} \mathrm{~Pa}$, the oxygen and argon gases (99.99\% purities) were introduced into the chamber through the mass flow controllers. The oxygen partial pressure and the total sputtering pressure were 0.25 and $2.0 \mathrm{~Pa}$, respectively. The sputtering was carried out using a constant current mode. The sputtering current was kept at $0.56 \mathrm{~A}$ and the sputtering power was about $235 \mathrm{~W}$. In order to remove surface contaminants of the target, pre-sputtering was done for 20 min with a shutter covering the substrate. The target-substrate distance varied from 50 to $90 \mathrm{~mm}$. The deposition time has been adjusted for the different target-substrate distance in order to get the films with the same thickness. All the films have a similar thickness about $1.8 \mu \mathrm{m}$ which are measured by FE-SEM. The transmittance of the films was measured using a Jasco V-550 UVvis spectrophotometer. The XRD measurements have been done using Rigaku miniflex goniometer $(30 \mathrm{kV}, 15 \mathrm{~mA})$. The morphologies of the nanorods were studied using field emission scanning electron microscope (FE-SEM). The crystal structure of the nanorods were observed using HR-TEM. Raman scattering measurements have been done using a semiconductor laser and a $532 \mathrm{~nm}$ laser line is used as exciting light. The laser line is focused on the sample surface in a strict $180^{\circ}$ backscattering geometry.

The deposited $\mathrm{TiO}_{2}$ films were sensitized with N719 (Ru(II)L2(NCS)2:2TBA, where $\mathrm{L}=2,2^{\prime}$-bipyridyl-4,4'-dicarboxylic acid) dye by soaking the films in an ethanolic solution of N719 dye $(0.5 \mathrm{mM})$ of for $24 \mathrm{~h}$ at room temperature. The counterelectrode was made by sputtering Pt on an FTO glass and the electrolyte is composed of $0.1 \mathrm{M} \mathrm{I}_{2}, 0.1 \mathrm{M}$ LiI, 0.6 M 1-hexyl-3methylimidazolium iodide, and $0.5 \mathrm{M}$ 4-tert-butylpyridine in 3methoxypropionitrile. The photocurrent-voltage measurements were carried out with a Princeton 2273 applied research electrochemical system, a $500 \mathrm{~W}$ Xenon lamp under AM 1.5G illumination with a water filter was used. The light intensity was adjusted to $100 \mathrm{~mW} / \mathrm{cm}^{2}$. Cells with an active area of $0.15 \mathrm{~cm}^{2}$ were tested.

\section{Results and discussion}

Fig. 1 shows the deposition rate of $\mathrm{TiO}_{2}$ nanorod at different target-substrate distances. The deposition rate decreases quickly from about 10 to $5 \mathrm{~nm} / \mathrm{min}$ as the target-substrate distance increases from 50 to $60 \mathrm{~mm}$. As the target-substrate increases further from 60 to $90 \mathrm{~mm}$, the deposition rate decreases gradually from 5 to $2 \mathrm{~nm} / \mathrm{min}$. This variation could be related with the collisions between the sputtered particles and inert and reactive gases in the vacuum chamber. At $2 \mathrm{~Pa}$ pressure and room temperature, the mean free path of the sputtered particles is about $5 \mathrm{~mm}$ and the collision times each second between sputtered particles and gas is in an order of ten thousands. As

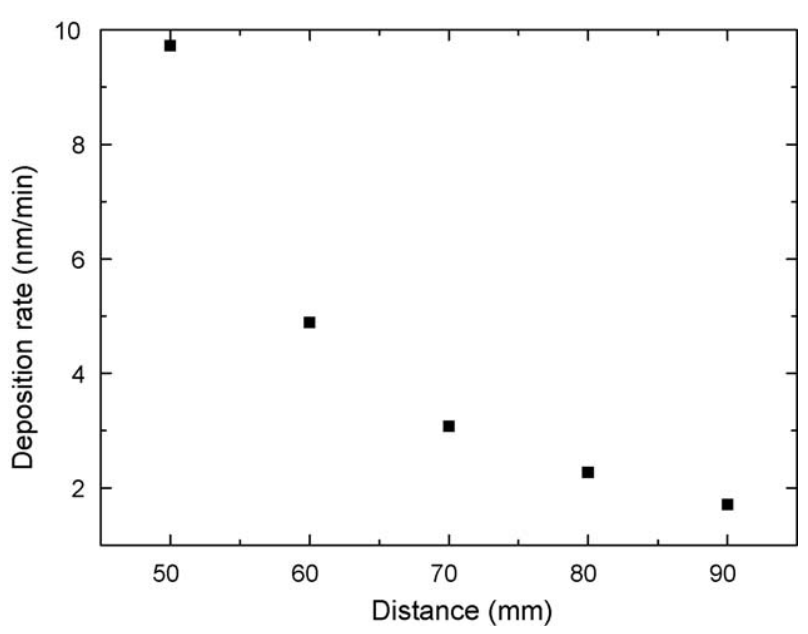

Fig. 1. Deposition rate as a function of the target-substrate distance.

the mean free path is less than the minimum target-substrate distance $(50 \mathrm{~mm})$, the titanium atoms will be scattered by the collisions when they travel from the target to substrate. When they are scattered by the gas in the vacuum chamber, the titanium atoms will be redirected away from the substrate. This scattering produces an exponential decay in the number of atoms that actually reach the substrate and results in a variation of the deposition rate as shown in Fig. 1.

The FE-SEM images of the nanorods sputtered at different target-substrate distances are shown in Fig. 2. It shows that highly ordered $\mathrm{TiO}_{2}$ nanorod arrays have been formed at different targetsubstrate distances. All these nanorods are perpendicular to the ITO substrate and have a similar thickness about $1.8 \mu \mathrm{m}$. It can be seen from the top view that the nanorods diameter decreases as the target-substrate distance is increased. When the targetsubstrate distance is less than $80 \mathrm{~mm}$, the morphology of the nanorod does not show a clear variation with the target-substrate distance. However, when the target-substrate distance is $90 \mathrm{~mm}$, the small nanorods are aggregated together and form the nanorods clusters which result in a relative rough surface. It can be observed that the nanorods with the big diameter are also composed of the small nanorods. As the target-substrate is increased, these big nanorods divide into the small nanorods. Although the small nanorods get together again when the target-substrate distance is $90 \mathrm{~mm}$, the aggregations are quite loose due to the low particles energy comparing to that at short target-substrate distance.

The formation of the $\mathrm{TiO}_{2}$ nanorods may be explained by considering the Thornton structure zone model [37,38]. Originally, the Thornton model was developed to describe the growth of sputtered metals in dependence of two parameters, substrate temperature and sputter pressure. According to this growth model, at low substrate temperature, the columnar structure with open voided boundaries (now it is called as nanorod arrays) will be formed at high sputtering pressure. Although the model is used for sputtered metals, it can also be used for the reactive sputtering process. It is well known that if the interaction energy between atoms of the substrate and the deposit (adhesion) is much larger than the interaction energy between atoms of the deposit (cohesion), a subsequent layer will grow after the previous layer is completed (layer growth). If the cohesion energy is larger than the adhesion energy, island growth takes place [39]. In this work, the island growth must dominate the growth process as the nanorods have been formed. For the island growth, the surface mobility of the adatoms is a very important parameter. At the high sputtering pressure, the surface adatom mobility is low as proposed by Thornton [37]. This means that the incoming 


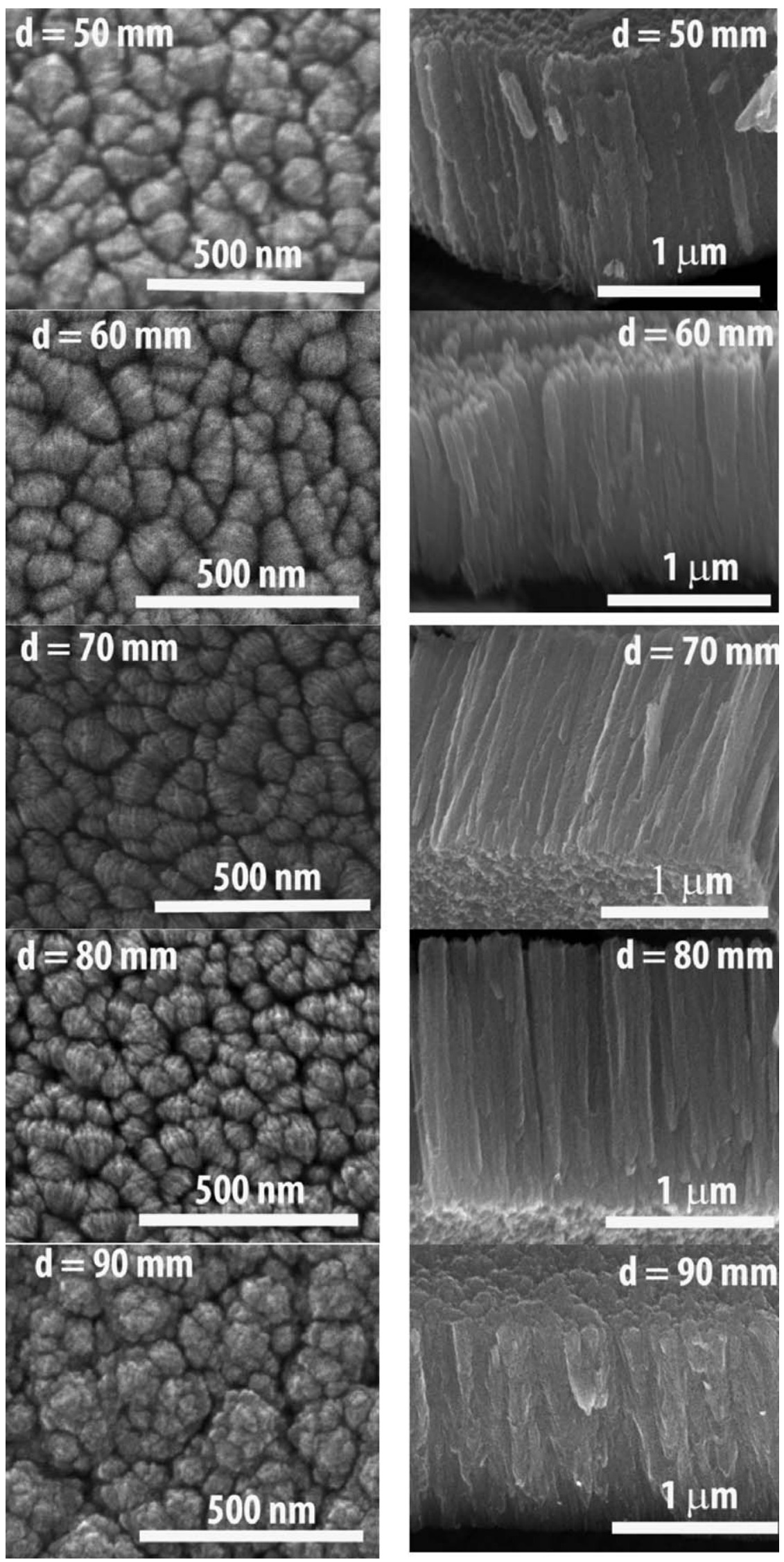

Fig. 2. FE-SEM images of $\mathrm{TiO}_{2}$ nanorods prepared at different target-substrate distances (left side: top view; right side: cross-section view). 
sputtered particles may stick where they arrive first and results in a columnar growth. The substrate will be bombarded continuously by energetic neutrals of inert gas during the deposition processes. This effect will be weakened as the target-substrate distance is increased. It means that at small target-substrate distance, the surface adatom mobility is higher than big target-substrate distance. Therefore, at small target-substrate distance, the incoming sputtered particles may still have some possibilities to migrate across the substrate surface after condensation to energetically preferred sites, where they nucleate. As the targetsubstrate distance is increased, the possibility of the migration of the sputtered particles decreases. Therefore, the diameter of the sputtered nanorod decreases as the target-substrate distance is increased.

The numbers of the nanorod prepared at different targetsubstrate distance have been counted and the nanorod density and the average nanorod diameter have been calculated as shown in Fig. 3. It can be seen that the nanorod diameter can be controlled by changing the target-substrate distance. As the target-substrate distance varies from 50 to $90 \mathrm{~mm}$, the nanorod diameter can be modified from 85 to $45 \mathrm{~nm}$. Therefore, it gives an easy way to control the nanorod diameter.

Fig. 4 shows the XRD patterns of the $\mathrm{TiO}_{2}$ nanorods prepared at different target-substrate distances. All the nanorods show only anatase phase (PDF card 21-1272), no other phase can be observed. When the target-substrate distance is shorter than $80 \mathrm{~mm}$, the sputtered nanorods show a very strong preferred orientation along the $\left[\begin{array}{lll}1 & 1 & 0\end{array}\right]$ direction. However, this preferred orientation totally disappeared as the target-substrate distance is $90 \mathrm{~mm}$. This variation may result from the variation of the structure as it has been seen from the SEM images. Most of the work reported in the literature on 1D nano-structured $\mathrm{TiO}_{2}$ materials are the $\left(\begin{array}{lll}1 & 0 & 1\end{array}\right)$ orientated anatase phase or mixed anatase and rutile phase

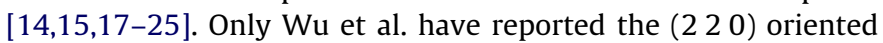
$\mathrm{TiO}_{2}$ nanorods prepared by MOCVD at high substrate temperature [16]. Fig. 5(a) shows a TEM image of an anatase nanorod prepared at $80 \mathrm{~mm}$ target-substrate distance. It can be seen that the nanorod is not smooth and shows a structure of ears of wheat. HR-TEM measurement has been performed for this nanorod as shown in Fig. 5(b). The inset of Fig. 5(b) is the electron diffraction (ED) pattern calculated using fast Fourier transform (FFT). The [ $\left[\begin{array}{lll}1 & 0 & 1\end{array}\right]$ crystal planes are observed very clearly in Fig. 5(b). However, the [ $\left.\begin{array}{lll}1 & 1 & 0\end{array}\right]$ crystal planes cannot be observed directly. From the ED pattern calculated using FFT, the diffraction spot of the [ $\left.\begin{array}{lll}1 & 1 & 0\end{array}\right]$ crystal plane can be viewed as shown in the inset of Fig. 5(b). Considering the angle between the [ $\left.\begin{array}{llll}1 & 0 & 1\end{array}\right]$ and the [ $\left.\begin{array}{lll}1 & 1 & 0\end{array}\right]$ crystal planes (about $68^{\circ}$ ), it can be concluded the direction of the [ $\left[\begin{array}{lll}1 & 1 & 0\end{array}\right]$

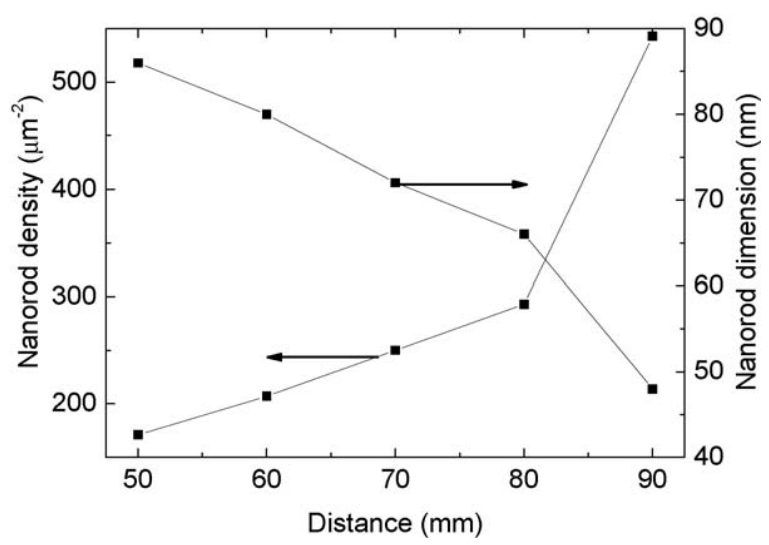

Fig. 3. Nanorod density and diameter as a function of the target-substrate distance.

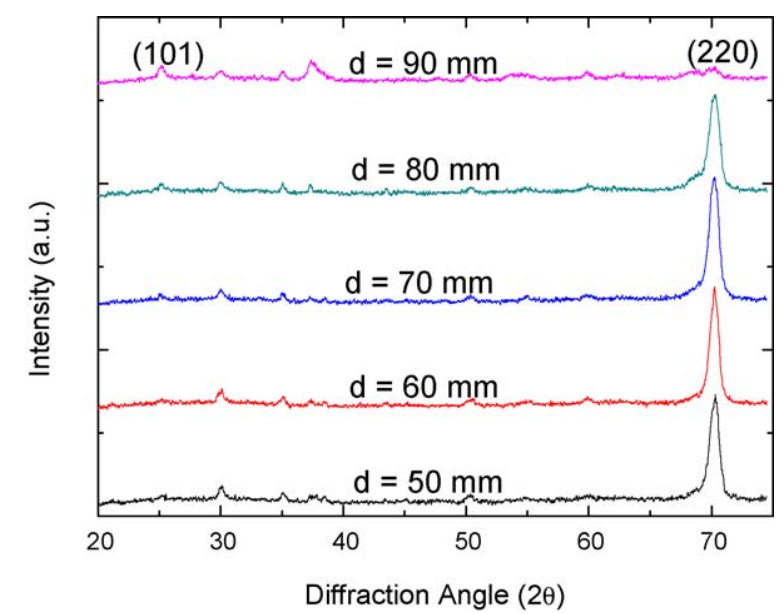

Fig. 4. X-ray diffraction patterns of $\mathrm{TiO}_{2}$ nanorods prepared at different targetsubstrate distances.

crystal plane is along the horizontal direction as indicated in Fig. 5(b). This result agrees well with the XRD measurement, which

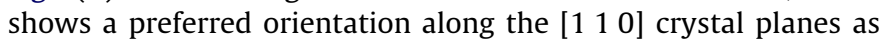
shown in Fig. 4. Although the nanorod is not smooth, the orientation of the different part in the nanorod is the same with a little distortion. By fitting the (2 20 ) diffraction peak, the distance

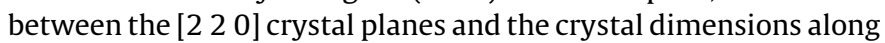

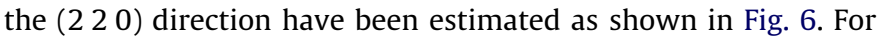
comparing, the standard value $\left(d_{0}=0.1338 \mathrm{~nm}\right)$ is also given in the figure. As the target-substrate distance is increased from 50 to $80 \mathrm{~mm}$, the distance between the [2 20 ] crystal planes is less than standard value and have a small increase, which means that there is a tensile stress in these nanorod arrays and the stress relaxes
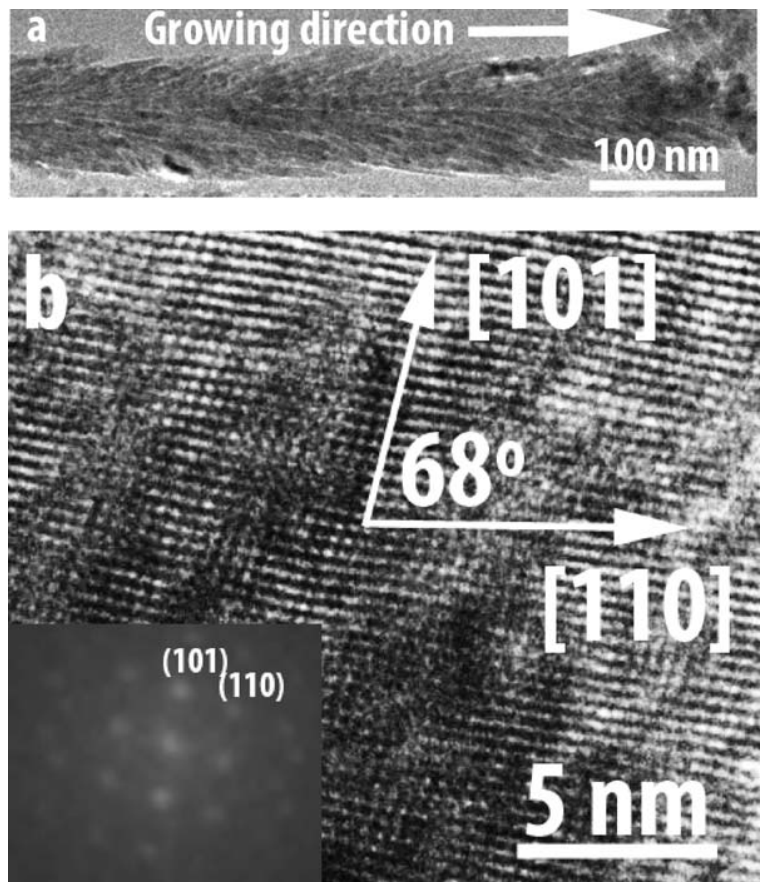

Fig. 5. (a) TEM image of an anatase $\mathrm{TiO}_{2}$ nanorod prepared at $80 \mathrm{~mm}$ targetsubstrate distance; (b) HR-TEM image of the part of the nanorod and the corresponding electron diffraction pattern calculated using fast Fourier transform (inset). 


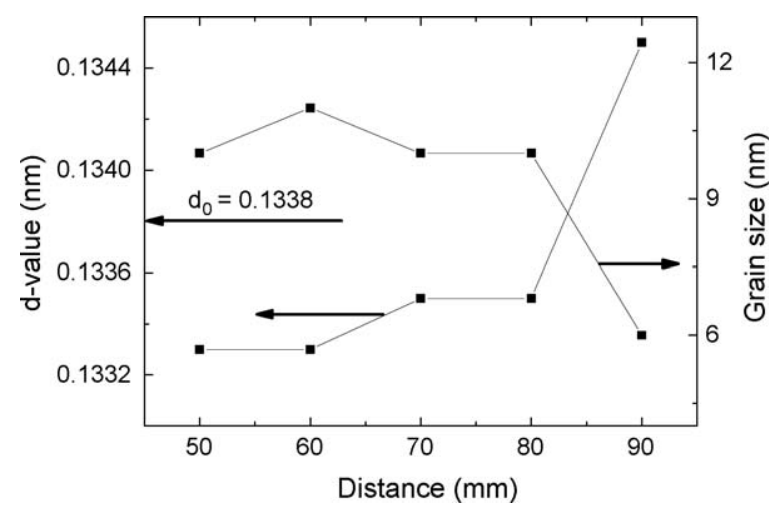

Fig. 6. The distance between the [2 20 0 crystal planes and the grain dimension along the $(220)$ direction as a function of the target-substrate distance.

with the increase of the distance. As the target-substrate distance

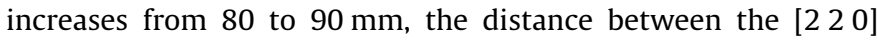
crystal planes is higher than standard values, it means the residual stress changes from tensile to compressive stress. The grain size along the (2 200$)$ direction is about $10 \mathrm{~nm}$ when the targetsubstrate distance is shorter than $80 \mathrm{~mm}$ and is about $6 \mathrm{~nm}$ when the distance is $90 \mathrm{~mm}$. It can be seen that the dimension along the nanorod growth direction is smaller than the lateral dimension.

Fig. 7 gives the Raman spectra of $\mathrm{TiO}_{2}$ nanorods prepared at different target-substrate distances. All five anatase phase Raman peaks can be observed even for $\mathrm{TiO}_{2}$ nanorods prepared at $90 \mathrm{~mm}$ target-substrate distance which shows a very weak XRD pattern as shown in Fig. 4. It means that Raman scattering can be used as a complementary technique to identify the phase when the XRD measurement could not give a clear result. The strongest $E_{\mathrm{g}}$ Raman peaks for $\mathrm{TiO}_{2}$ nanorods prepared at different target-substrate distance have been fitted and the peak position and FWHM are ploted in Fig. 8. All the peak positions have been calibrated by taking the $\mathrm{TiO}_{2}$ powder (P25) peak value as $143 \mathrm{~cm}^{-1}$. It can be seen that the $143 \mathrm{~cm}^{-1} E_{\mathrm{g}}$ vibration mode diverge gradually from the standard value as the target-substrate distance is increased. This divergence is related both with the stoichiometry of $\mathrm{TiO}_{2}$ material [40] and the residual stress in $\mathrm{TiO}_{2}$ material [41]. The $E_{\mathrm{g}}$ peak width shows a small variation as the substrate-target distance varies from 50 to $80 \mathrm{~mm}$ and then a clear increase as the distance varies from 80 to $90 \mathrm{~mm}$. This great increase of the peak width may be related to the structure variation as have been confirmed by SEM and XRD measurements.

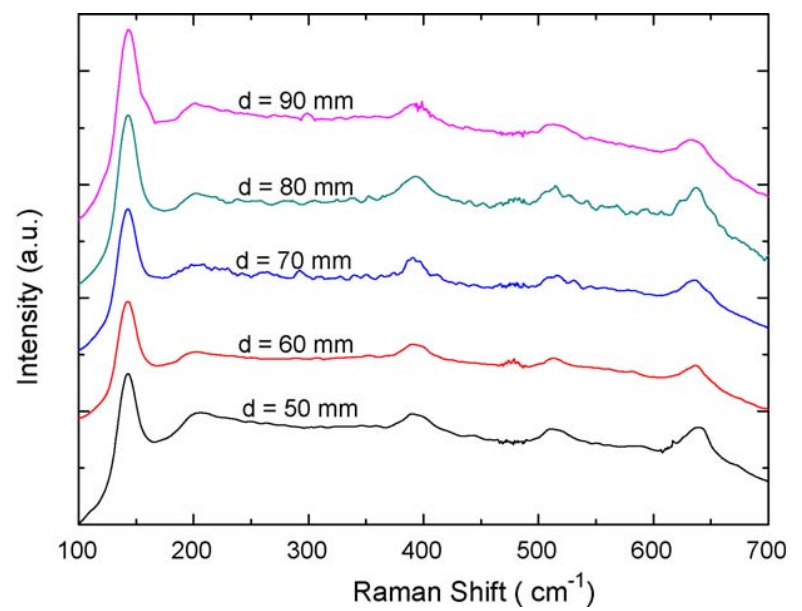

Fig. 7. Raman spectra of $\mathrm{TiO}_{2}$ nanorods prepared at different target-substrate distances.

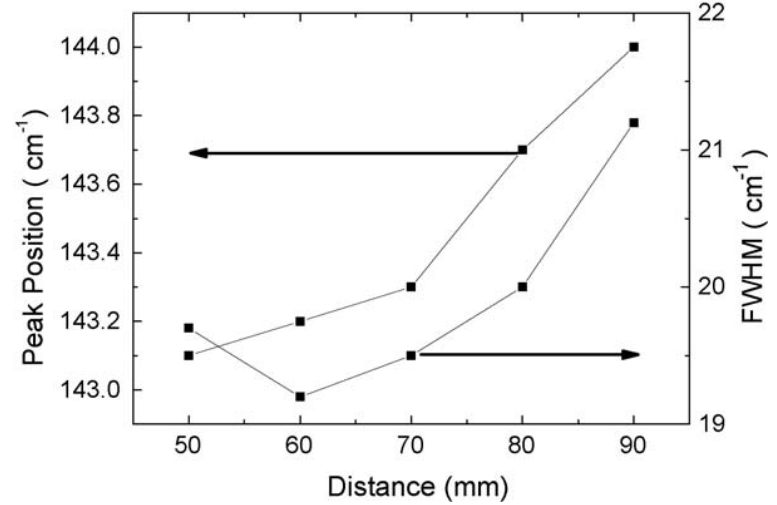

Fig. 8. Raman peak position and peak width as a function of the target-substrate distance.

The transmittance of the $\mathrm{TiO}_{2}$ nanorods prepared at different target-substrate distances are given in Fig. 9. In the visible region, the transmittance is about $80 \%$. This is a quite good transmittance for a film with about $1.8 \mu \mathrm{m}$ thickness. The same thickness $\mathrm{TiO}_{2}$ film prepared by chemical method only has $60 \%$ transmittance [4]. It can be seen that the transmittance of the $\mathrm{TiO}_{2}$ nanorods has a small decrease as the target-substrate distance is increased. The interference fringe almost disappears for $\mathrm{TiO}_{2}$ nanorods prepared at $90 \mathrm{~mm}$ target-substrate distance. From the SEM images it can be seen that the nanorods prepared at this distance is quite nonuniform and results in the disappearance of the interference fringe.

The DSSC devices were built using these $\mathrm{TiO}_{2}$ nanorod arrays as the photoelectrode and the photoelectric properties were characterized. Fig. 10 compares the photocurrent density-voltage $(J-V)$ curves of the DSSC using the $\mathrm{TiO}_{2}$ nanorod arrays prepared at different target-substrate distances as the working electrodes. The short-circuit photocurrent density $\left(J_{s c}\right.$, short-circuit photocurrent $I_{\mathrm{sc}}$ divided by the area of the cell), open circuit voltage $\left(V_{\mathrm{oc}}\right)$, fill factor (FF) and light-to-electricity conversion efficiency $(\eta)$ of the cells are shown in Fig. 11. The fill factor is calculated from the maximum power point defined by the square of the $I-V$ curve. $\mathrm{FF}=P_{\mathrm{max}} / V_{\mathrm{oc}} J_{\mathrm{sc}}$, and $P_{\mathrm{max}}=V_{\mathrm{mp}} I_{\mathrm{mp}}$, where $P_{\max }$ is the maximum power, $V_{\mathrm{mp}}$ and $I_{\mathrm{mp}}$ are voltage and current corresponding to the maximum power in $I-V$ curve. The energy conversion efficiency is given by $\eta=P_{\text {max }} / P_{\text {in }}=V_{\text {od }} J_{\mathrm{sc}} \mathrm{FF} / P_{\text {in }}$, where $P_{\text {in }}$ is the total light power incident on the cell.

It can be seen that the FF and $V_{\text {oc }}$ do not show a very clear variation as the target-substrate distance is varied from the 40 to

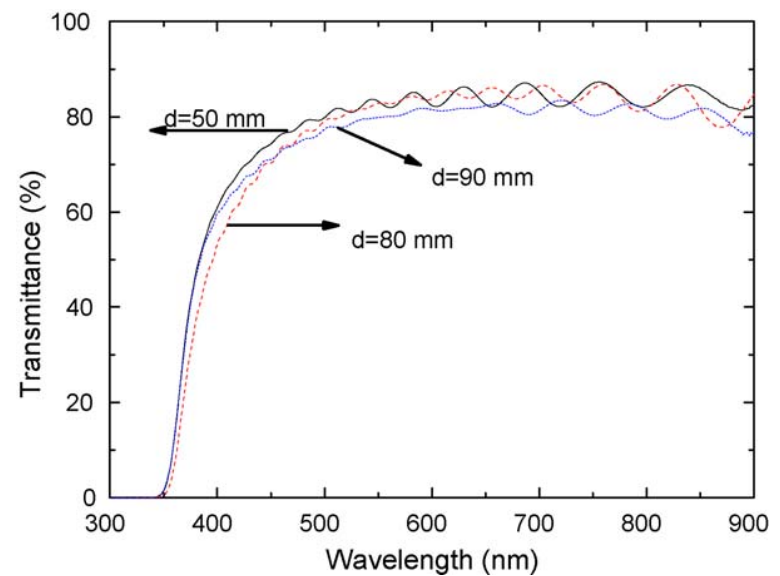

Fig. 9. Optical transmittance of $\mathrm{TiO}_{2}$ nanorods prepared at different target-substrate distances. 


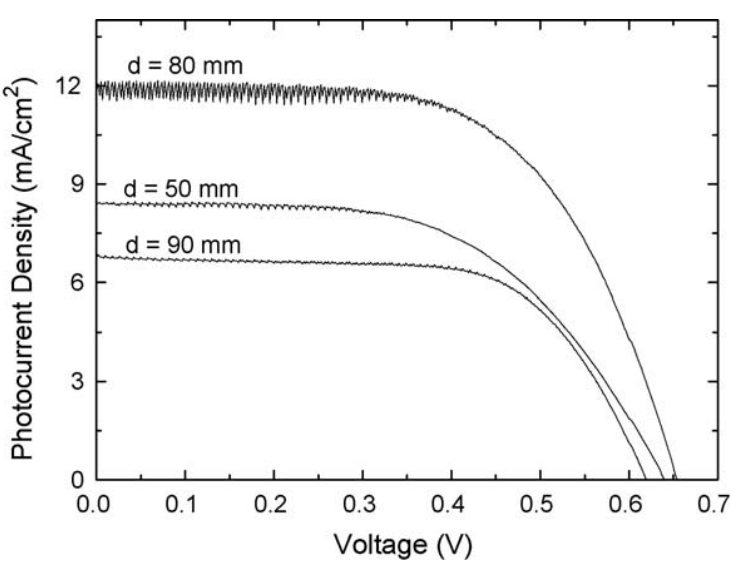

Fig. 10. $J-V$ curves for DSSC with $\mathrm{TiO}_{2}$ nanorods prepared at different targetsubstrate distances.

$70 \mathrm{~mm}$. It is known that the FF is related to the series resistance for a practical solar cells and $V_{\text {oc }}$ is most likely related with the difference between the Fermi level of $\mathrm{TiO}_{2}$ electrode and the electrochemical potential of the electrolyte (the redox couple). It means that the nanorod diameter does not affect practically the series resistance of the DSSC device and the Fermi level of $\mathrm{TiO}_{2}$ electrode. However, the $J_{\text {sc }}$ shows a very clear increase as the target-substrate distance is increased and the conversion efficiency also shows a similar variation as the $J_{\mathrm{sc}}$ does. Although many parameters can influence the conversion efficiency of the DSSC device, $J_{s c}$ is the key parameter that governs the DSSC conversion efficiency. The results shown in Fig. 11 are agreeable with this point.

The photocurrent density $J_{s c}$ is related to the number of photogenerated electrons which are efficiently transferred to TCO

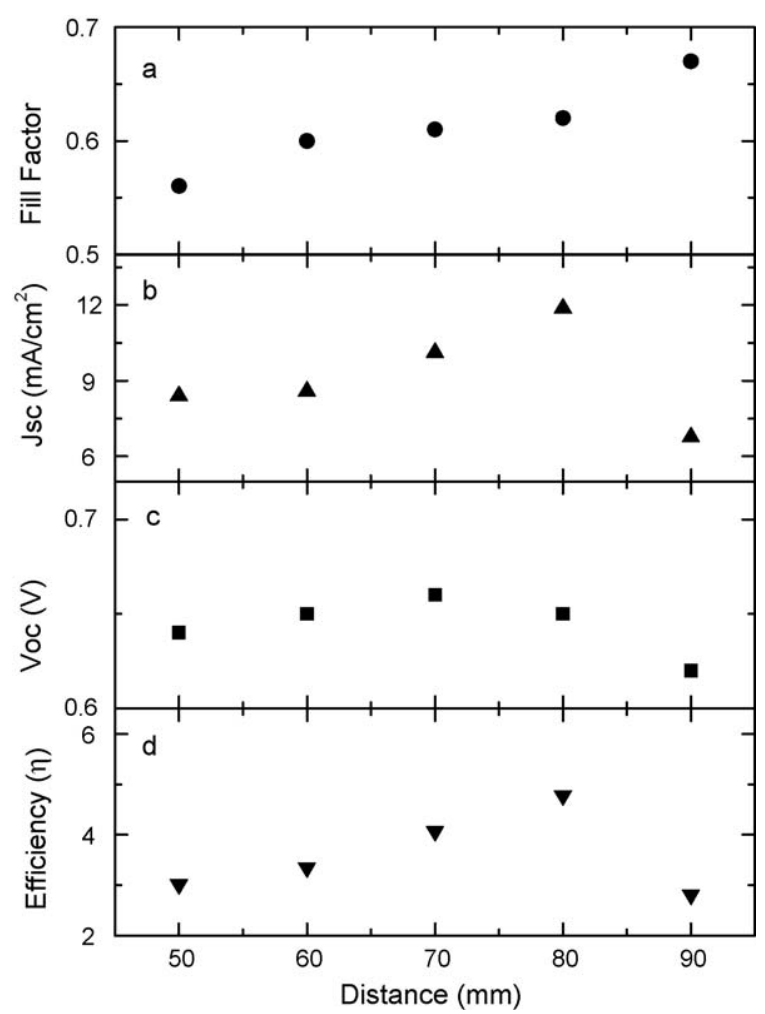

Fig. 11. The variations of fill factor (a), short-current density (b), open-current voltage (c), and conversion efficiency (d) with the target-substrate distance. electrode. The kinetic equation for the 1D current density $J_{n}(x)$ has been described by Gregg as [42]:

$$
\left.J_{n}(x)=n(x) \mu_{n}(\nabla U(x))+\nabla \mu(x)\right)
$$

where $n(x)$ is the concentration of electrons, which depends on the amount of the electron injected by the dye; $\mu_{n}$ is the electron mobility; $U(x)$ and $\mu(x)$ are the electrical and chemical potential, respectively, which are constant for a given materials system. The carrier motion is through either diffusion (driven by concentration gradient) or drift (driven by an electric field). The electron transport in DSSC occurs in the presence of an electrolyte, which screens the macroscopic electric fields, and therefore, electron transport in DSSC is mainly due to the diffusion. As it can be seen from Fig. $11 \mathrm{~b}$, the $J_{\mathrm{sc}}$ is increased as the target-substrate distance increases from 50 to $80 \mathrm{~mm}$ and then goes down as the distance is increased further. This variation of the $J_{\mathrm{sc}}$ can be explained using the equation introduced by Gregg. Firstly, as it can be seen from Fig. 3, the nanorod diameter decreases as the target-substrate distance increases. The small diameter will increase the surface area and the amount of the dye molecules anchored on the surface is also increased. Fig. 12 shows the dye absorption for $\mathrm{TiO}_{2}$ nanorods prepared at different target-substrate distance. From the dye absorption band near the $520 \mathrm{~nm}$, it can be seen that as the target-substrate distance is varied from 50 to $80 \mathrm{~mm}$, the dye absorption is increased. Although the nanorod prepared at $90 \mathrm{~mm}$ distance has the smallest diameter, many of them are congregated together and result in a poor absorption of the dye molecules. Secondly, 1D nano-structured $\mathrm{TiO}_{2}$ electrode based DSSC have a significantly higher charge collection efficiencies than nanoparticles $\mathrm{TiO}_{2}$ electrode based DSSC [43]. In addition, the reduction of diameter of the 1D structure makes the electron flow more channeled [44]. This more channeled electron flow makes the electron transport more efficient. It means the nanorods with small diameter will improve the charge mobility and then an increase of the $J_{\mathrm{sc}}$. Considering both of these factors, the maximum $J_{\mathrm{sc}}$ $\left(11.88 \mathrm{~mA} / \mathrm{cm}^{2}\right)$, and then the highest conversion efficiency (4.78\%) has been obtained for DSSC assembled with $\mathrm{TiO}_{2}$ nanorod arrays prepared at $80 \mathrm{~mm}$ target-substrate distance as shown in Fig. 11. It is a relative high conversion efficiency considering the thickness. It can be seen from Fig. 2 that our $\mathrm{TiO}_{2}$ nanorods have highly ordered structure. The highly ordered nanorods are favorable for electron transportation and may result in this high efficiency. It has been found that for disordered 1D nano-structure $\mathrm{TiO}_{2}$ electrode, more thickness is necessary for achieving a high efficiency [17]. For highly ordered $1 \mathrm{D}$ nano-structure $\mathrm{TiO}_{2}$

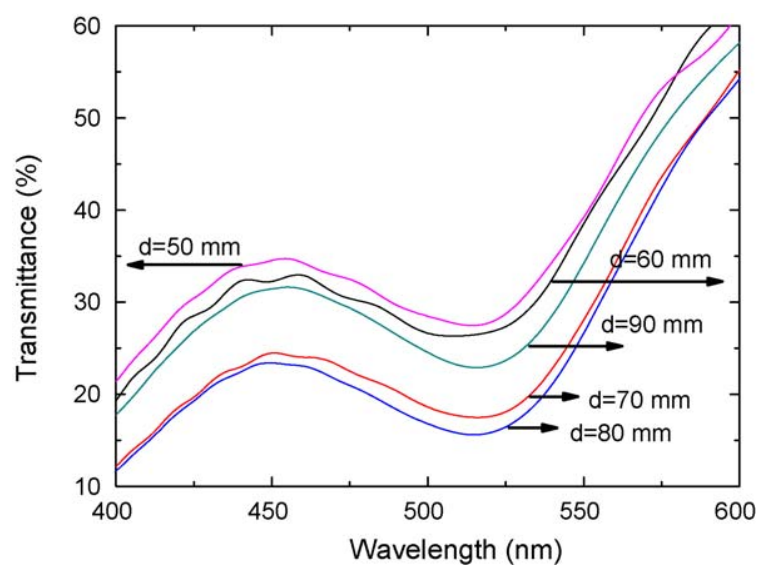

Fig. 12. Optical transmittance of $\mathrm{TiO}_{2}$ nanorods prepared at different targetsubstrate distances after dye absorption. 
electrode, high efficiency can be achieved with small thickness $[22,23]$.

\section{Conclusion}

In summary, $\mathrm{TiO}_{2}$ nanorod arrays have been successfully deposited on ITO substrate at room temperature by dc reactive magnetron sputtering. The diameter of these nanorods can be controlled by changing the target-substrate distance. The nanorods with different diameters have been used in DSSC as the electrodes. A maximum light-to-electricity conversion efficiency of $4.78 \%$ was achieved by using $65 \mathrm{~nm}$ diameter and $1.8 \mu \mathrm{m}$ length nanorod arrays as electrode.

\section{Acknowledgments}

This work was done during Lijian Meng's sabbatical stay in DICP (SFRH/BSAB/862/2008, FCT, Portugal) and was supported by the Solar Energy Action Project of the Chinese Academy of Sciences. The authors thank Mr. Xuming Wei, and Mr. Shishan Sheng from the State Key Laboratory of Catalysis, DICP for their assistances in SEM, HR-TEM and XRD characterizations. Lijian Meng would like to thank Dr. Fengqiang Xiong and Dr. Sheng Liu from DICP for illuminating discussions.

\section{References}

[1] B. O'Regan, M. Gratzel, Nature 353 (1991) 737-740.

[2] M. Gratzel, Inorg. Chem. 44 (2005) 6841-6851.

[3] Y. Chiba, A. Islam, R. Komiya, N. Koide, L. Han, Appl. Phys. Lett. 88 (2006) 223505.

[4] M.C. Kao, H.Z. Chen, S.L. Young, C.Y. Kung, C.C. Lin, Thin Solid Films 517 (2009) 5096.

[5] Y.J. Kim, M.H. Lee, H.J. Kim, G. Lim, Y.S. Choi, N.G. Park, K. Kim, W.I. Lee, Adv. Mater. 21 (2009) 1.

[6] L.S. Mende, M. Gratzel, Thin Solid Films 500 (2006) 296.

[7] C.Y. Huang, Y.C. Hsu, J.G. Chen, V. Suryanarayanan, K.M. Lee, K.C. Ho, Sol. Energy Mater. Sol. Cells 90 (2006) 2391

[8] J.K. Lee, B.H. Jeong, S.I. Jang, Y.S. Yeo, S.H. Park, J.U. Kim, Y.G. Kim, Y.W. Jang, M.R Kim, J. Mater. Sci.: Mater. Electron. 20 (2009) S446.

[9] J. Wu, S. Hao, J. Lin, M. Huang, Y. Huang, Z. Lan, P. Li, Cryst. Growth Des. 8 (2008) 247.

[10] N.G. Park, G. Schlichthorl, J. Van de Lagrmatt, H.M. Cheong, A. Mascarenhas, A.J. Frank, J. Phys. Chem. B 103 (1999) 3308.

[11] K. Hou, B. Tian, F. Li, Z. Bian, D. Zhao, C. Huang, J. Mater. Chem. 15 (2005) 2414
[12] M. Wei, Y. Konishi, H. Zhou, M. Yanagida, H. Sugihara, H. Arakawa, J. Mater. Chem. 16 (2006) 1287.

[13] D. Chen, F. Huang, Y. Cheng, R.A. Caruso, Adv. Mater. 21 (2009) 1.

[14] Y. Suzuki, S. Ngamsinlapasathian, R. Yoshida, S. Yoshikawa, Cent. Eur. J. Chem. 4 (2006) 476.

[15] B. Liu, E.S. Aydil, J. Am. Chem. Soc. 131 (2009) 3985-3990.

[16] J. Wu, C. Yu, J. Phys. Chem. B 108 (2004) 3377-3379.

[17] S.H. Kang, S.H. Choi, M.S. Kang, J.Y. Kim, H.S. Kim, T. Hyeon, Y.E. Sung, Adv. Mater. 20 (2008) 54-58.

[18] J. Jiu, S. Isoda, F. Wang, M. Adachi, J. Phys. Chem. B 110 (2006) 2087-2092.

[19] A. Wolcott, W.A. Smith, T.R. Kuykendall, Y. Zhao, Z. Zhang, Small 5 (2009) 104

[20] S. Ngamsinlapasathian, S. Sakulkhaemaruethai, S. Pavasupree, A. Kitiyanan, T. Sreethawong, Y. Suzuki, S. Yoshikawa, J. Photochem. Photobiol. A 164 (2004) 145.

[21] Y. Ohsaki, N. Masaki, T. Kitamura, Y. Wada, T. Okamoto, T. Sekino, K. Niihara, S. Yanagida, Phys. Chem. Chem. Phys. 7 (2005) 4157.

[22] G.K. Mol, K. Shankar, M. Paulose, O.K. Varghese, C.A. Grimes, Nano Lett. 6 (2006) 215-218.

[23] X. Feng, K. Shankar, O.K. Varghese, M. Paulose, T.J. Latempa, C.A. Grimes, Nano Lett. 8 (2008) 3781

[24] M. Law, L.E. Greene, J.C. Johnson, R. Saykally, P. Yang, Nat. Mater. 4 (2005) 455

[25] M. Adachi, Y. Murata, J. Takao, J. Jiu, M. Sakamoto, F. Wang, J. Am. Chem. Soc. 126 (2004) 14943.

[26] M.M. Gomez, N. Beermann, J. Lu, E. Olsson, A. Hagfeldt, G.A. Niklasson, C.G. Granqvist, Sol. Energy Mater. Sol. Cells 76 (2003) 37-56.

[27] M. Gomez, J. Rodriguez, S.E. Lindquist, C.G. Granqvist, Thin Solid Films 342 (1999) $148-152$.

[28] M. Gomez, E. Magnusson, E. Olsson, A. Hagfeldt, S.E. Lindquist, C.G. Granqvist, Sol. Energy Mater. Sol. Cells 62 (2000) 259-263.

[29] M. Gomez, J. Lu, E. Olsson, A. Hagfeldt, C.G. Granqvist, Sol. Energy Mater. Sol. Cells 64 (2000) 385-392.

[30] M. Gomez, J. Lu, J.L. Solis, E. Olsson, A. Hagfeldt, C.G. Granqvist, J. Phys. Chem. B 104 (2000) 8712-8718.

[31] Y.M. Sung, H.J. Kim, Thin Solid Films 515 (2007) 4996-4999.

[32] Ab. Benyoucef, Am. Benyoucef, F. Lapostolle, D. Klein, B. Benyoucef, J. Electron. Devices 5 (2007) 159.

[33] M.F. Hossain, S. Biswas, T. Takahashi, Y. Kubota, A. Fujishima, Thin Solid Films 516 (2007) 7149-7154.

[34] S.H. Kang, M.S. Kang, H.S. Kim, J.Y. Kim, Y.H. Chung, W.H. Smyrl, Y.E. Sung, J. Power Sources 184 (2008) 331

[35] S.H. Kang, J.W. Lim, H.S. Kim, J.Y. Kim, Y.H. Chung, Y.E. Sung, Chem. Mater. 21 (2009) 2777.

[36] S.M. Waita, J.M. Mwabora, B.O. Aduda, G.A. Niklasson, S. Lindquist, C.G. Granqvist Afr. J. Sci. Technol. 7 (2006) 106

[37] J.A Thornton, J. Vac. Sci. Technol. 11 (1974) 666

[38] J.A. Thornton, J. Vac. Sci. Technol. 12 (1975) 830

[39] K. Reichelt, Vacuum 38 (1988) 1083.

[40] J.C. Parker, R.W. Siegel, J. Mater. Res. 5 (1990) 1246.

[41] G.J. Exarhos, N.J. Hess, Thin Solid Films 220 (1992) 254.

[42] B.A. Gregg, J. Phys. Chem. B 107 (2003) 4688.

[43] K. Zhu, N.R. Neale, A. Miedaner, A.J. Frank, Nano Lett. 7 (2007) 69.

[44] R. Jose, V. Thavasi, S. Ramakrishna, J. Am. Ceram. Soc. 92 (2009) 289. 